\title{
Reconnecting actions and consequences
}

\author{
Peter Gall Krogh ${ }^{1}$, Martin Ludvigsen¹, Marianne Graves Petersen \\ ${ }^{1}$ Aarhus School of Architecture, Department of Design, Nørreport 20, DK-8000 Århus \\ Aarhus University, Department of Computer Science, Åbogade 34, DK-8200 Århus N \\ Peter.krogh@aarch.dk, martin.ludvigsen@aarch.dk,mgraves@cs.au.dk
}

\begin{abstract}
In this paper we present a brief critique of the current approach to the design of pervasive computing artifacts; claiming that this in itself promotes solutions that prevent end-users from accessing and understanding the consequences of their actions in terms of energy sustainability, specifically the use of electricity. We provide descriptions and cases of two strands to be explored which promote userengaging transparency and awareness of energy use and which consider the possibility of the production of electricity by individuals. Finally, a list of articles for governing the perspective is presented.
\end{abstract}

Keywords: Interaction Design, sustainability design articles, energy consumption, personal energy production.

\section{THE FLAWS OF PERVASIVENESS}

Interaction design is not currently part of the solution to the climate crisis. Rather it is part of the problem. Our aim as interaction designers - unconscious or not - is to send out yet more new gadgets, interfaces, diodes, and LED-displays, sensors, buttons and systems into the world regardless of the increased consumption of electricity this all entails. That's seen to be someone else's problem. Or is it?

There are many aspects of sustainability, which relate to $\mathrm{HCl}$, interaction design and the development of new technologies. These revolve around the increasing cycle of consumption, the efficiency of systems and the power and materials that go into the production and use of the technologies we might design. For the last 15-20 years, when asked to explain the notion of 'pervasive' and 'ubiquitous' to community outsiders, for many of us electrical power has been the most illustrative ready-at-hand example of something ever-present. It is everywhere. One simply reaches out one's arm, touches a switch and by the magic of industrial civilization, anything can be powered. We rarely - even abstractly - understand or think of the effort and energy that has gone into realizing this situation, nor what we currently use the power for. This amazing infrastructure and accessibility is the vision of ubiquitous computing. Making any information or resource available at your fingertips, for example "Moving two tons of tomatoes from Spain to Denmark is only one click away". This is deeply impressive or rather worrying, depending on your perspective.

In line with [0] we claim that this approach to ubiquitous computing adds another layer of experiential insulation in addition to the way in which the industrial revolution separated people from recognizing the (environmental) consequences of their actions. We are not agitating for a "before the modern world romanticism," removing pervasive and ubiquitous computing from our life. The potential benefits are too far-reaching, efficient and, not least, they are fun. What we propose is to alter the design approach to use ubiquitous computing and related technologies in the service of reestablishing the experiential connection between human actions and environmental consequences.

\section{RECONNECTING}

The increasing experiential gap between human actions and the comprehension of their consequences can be illustrated in a similar fashion to the electricity metaphor for ubiquitous 
computing that was mentioned earlier. Before electricity we'd light a candle to see in the dark; with electricity lights come on by flicking a switch. By means of desktop and ubiquitous computing we can control light anywhere in a household or at a distance in a summerhouse. Furthermore buildings equipped with lightweight computational devices turn lights on and off dependent on human movement.

Humans pick up habits fast. Having learned that light automatically comes on and off in one environment dependent only on our presence, we then expect that to happen everywhere. This can means that rooms unequipped with sensors remain fully lit at anytime of the day. Turning on and off the light is no longer our responsibility. Lighting a candle on the other hand makes us aware that certain local resources are needed: fire, friction that lights the sulfur, for example. And furthermore when the candlelight is blown out there is leftover material in the burned-out matchstick, the paraffin in the candle, the smoke that comes from there and the smell that lingers in the room. These experiential qualities appeal strongly to us and mean we still use the candle despite its obvious drawbacks and limitations.

Several genres of research have promoted alternative ways for interacting with the pervasiveness of information and connectivity. One of the most prominent examples is tangible computing, where designers and developers have tried to reformulate human-computer interaction such that it accounts for our physical and social context, enabling experiential richness, exploiting bodily and spatial qualities $[0,0]$.

In similar terms what we might call sustainable interaction should promote a (re)connection of what we do, to the effect it has on the consumption of shared resources, thus making the consumption of energy an integral and visible part of the interaction. An example could be making electricity a resource that should be negotiated at each meeting by simply limiting power supplies, so each person's use has an impact on the whole group's available resources.

It might even be so that, in relation to our environmental impact and what interaction design can do to reduce or reframe this, the challenge of connecting users to a clearer understanding of their actions is even bigger than with tangible interaction. In addition, interaction design could also take a leading role in reconnecting people to the context in which they consume resources, in this case electricity.

\section{DESIGN APPROACH AND STRANDS}

Reconnecting people to the consequences of their actions must not become a mission indulged with sacrifice, guilt, pointing fingers and limitations on the quality of life. Rather it should aim at infusing a positive and deeper understanding that until now has been residing in the background. Not by malevolent opposition, but by lack of useful concepts, perspectives, and due models. In the following we propose two strands to be explored while recognizing there probably are many more. While one strand focuses on an awareness of collective accessibility, the other focuses on the individual production of electricity. Both strands pursue inspiring the user in ways that might lead to a culture more conscious of power consumption and, taking advantage of expressive interaction, approaches that promote a new generation of devices, services and systems.
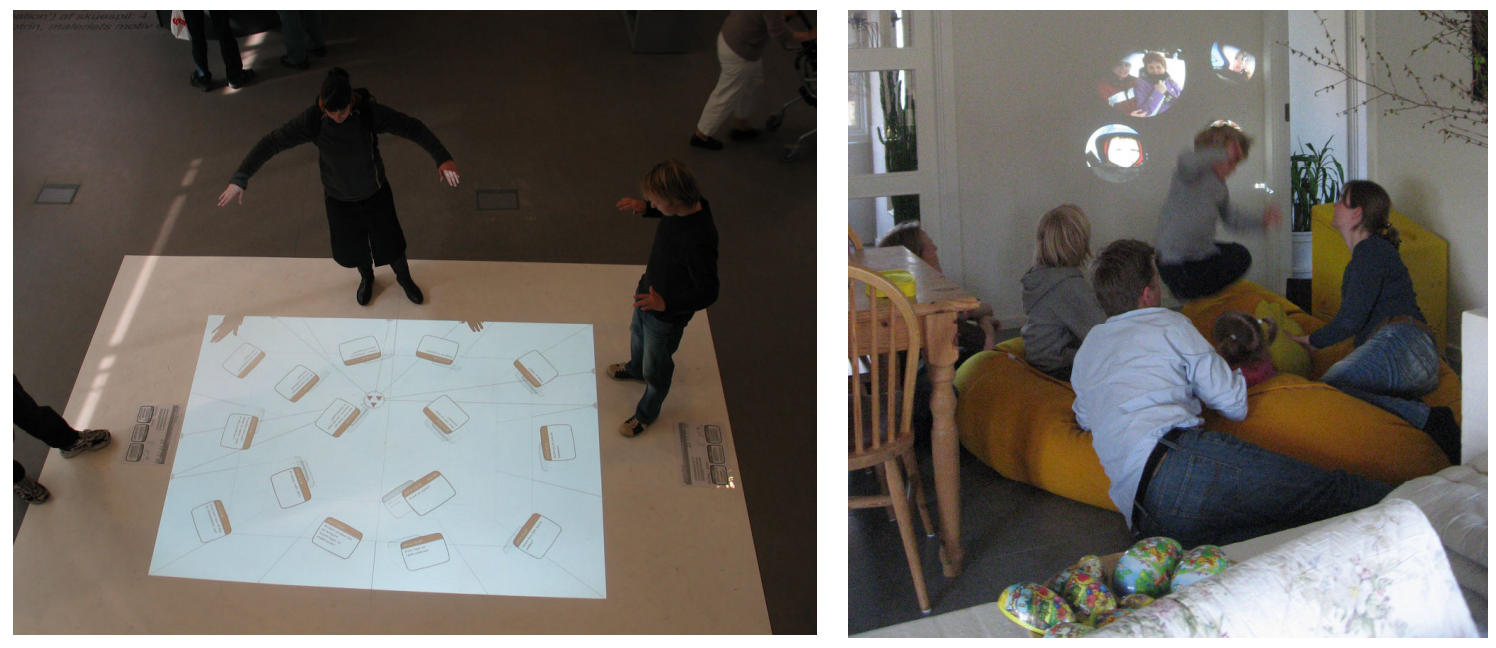
FIGURE 1: iFloor (to the left) is an Interactive floor, navigated with one shared cursor and controlled by video tracking body movements around the floor. Interaction must be negotiated by everyone around the floor to work; a kind of 'forced collaboration' similar to physical resources in physical space. Squeeze (to the right) is an interactive sack chair for controlling digital photos - physical activity affects the displayed imagery, thus again demanding negotiation and making interaction with the shared digital resources very visible in the shared physical context.

\subsection{Collective interaction}

In everyday use electricity is a shared and seemingly inexhaustible resource. It is only when "black-outs" occur due to excessive demand that we become aware of the limits of the system. There are no means for the individual to understand the effects of their share of demand on the system due to its size and complexity.

We know from numerous social situations that humans are highly skilled in respectfully sharing resources in a collective when the resources are visible and the means for negotiation are understandable e.g. sharing a meal. At a glance we can estimate the quantity of food, compare it with the number of participants and use etiquette to deduce how much we are permitted to transfer to our own plate. We have explored this principle through the concept of Collective Interaction [0], developed and tested outside the domain of sustainability. The two prototypes (figure 1) $[0,0]$ referenced here present ways of sharing computers among co-located people and are examples of what we denote collective interaction. Collective interaction is intended to counteract the highly individualistic approach to interaction design, where commercially available devices are typically designed for maximum individual control. Collective Interaction does not imply an ideal of efficiency, but rather an ideal of use being socially negotiated and expressed in the physical context. The users are depending on individual actions, fostering an extended sociality beyond the actual interactive system, sociality by the system rather than through the system. From the perspective of the use-situation, the question of interest is changed from "what it is that I/ you want?" to "what desirable place or situation are we forming together?"

\subsection{From passive consumer to involved producer:}

Interactive systems design is about shaping the exchange between the human component, person or user, and the system component or computer. We propose to extend this to a use situation where the workings of the computer artifact are dependent on the energy created by the human, thus forming an integrated flow of energy. An example of this could be running gear such as devices for measuring pulse, distance etc. which are powered by the collected energy from human motion. Other appropriate applications of human powered appliances would be small devices such as TV-remotes, kitchen weights or tea-timers, which are normally driven by batteries. A range of technologies already exists for exploiting and collecting kinetic energy from small-scale movements. Quick, simple human movements could power these devices for the short duration we need them. One could even imagine that out of boredom, or over eagerness in exercise some people would produce more electricity than they could consume so enabling them to share it with friends. Expanded further, this would surely move the individual not only from passive consumer to involved producer but perhaps even to become a retailer of selfproduced electricity. Today in several countries systems already exist where private producers of energy (e.g. solar or wind power) can sell their production back to the Grid, as long as their overall production does not exceed their total annual use. Basically one is using the national grid as a battery for the household. The size of the self-produced kinetic energy economy developed on this basis would probably never grow to a large-scale, but the effect on energy awareness and the power that goes into electricity production could be tremendous, as it would happen on a human-to-human scale. And the potential for designing inspiring ways of exchanging this energy could elicit new forms of explicit social interaction.

\section{7 DESIGN ARTICLES GOVERNING THIS PERSPECTIVE}

Inspired by John Thackara's 10 Articles associating designers, technology developers and users [0] below we suggest articles (a list to be extended) that should govern the perspective presented here:

1. IT-appliances should be designed to at least produce the same amount of power as it consumes to work. All interactions with technology should aim at being carbon-neutral, independent and self-reliant. We should design for local and personal power generation and exchange 
2. People are helpful. Design solutions take advantage of social negotiation of resources and collective action

3. People are more adventurous than lazy. Sustainable interaction should transcend easeof-use. They like to do things, share things and to feel cool

4. People don't like to feel guilty. A bad consciousness does not change the habits of people. It is what we love that makes us change habits - we should design for desire rather than guilt.

5. People are smart - when hit by economic penalty they develop workarounds - financial decoy birds is not enough to change habits - we need to design for benefits rather than penalties.

6. Make transparent solutions. The consequences of our actions, good or bad, should be perceivable by the design - not hidden away.

7. Limitations rarely work. We should not design limits to people's ability to express themselves, but inspire them to appreciate that what they do has consequences for others, and leave the systems open for reconfiguration.

\section{WRAP UP}

The perspective on sustainability promoted by engaging interaction design as presented here is very much driven by design. We have focused on experiential, aesthetic and social qualities in interacting with computational systems and the exploitation of human powered devices. These are means for reconnecting people to the consequences of their actions, with the aim of improving energy sustainability in terms of electricity. Many aspects of the matter are left unexplored: What will happen when individuals are capable of selling individually produced energy? Which technologies show the best promise? There is obviously a wealth of technologies e.g. pico sensors and smart textiles that support the overall concept, but rather than looking at specific existing technologies and how these might be used, we are pointing at some of the key human desires and capabilities that should inform the pursuit and further the technology developments. Our basic claim is that if it is not happening at a human scale, and is neither fun nor cool to use then the success will be limited - this is a matter of interaction design.

\section{REFERENCES}

[1] Djajadiningrat, T., Matthews, B., Stienstra, M.(2007): Easy doesn't do it: skill and expression in tangible aesthetics. Personal and Ubiquitous Computing Volume 11, Issue 8 (December 2007), Pages: 657 - 676. Springer-Verlag London, UK

[2] Dourish P (2001) Where the action is: the foundations of embodied interaction. MIT, Cambridge

[3] Krogh, P.G., Lykke-Olesen, A., Ludvigsen, M.,(2004): Help me pull that cursor. In Proceedings of Ozchi2004, Sydney

[4] Krogh, P. G. and Petersen, M. G. (2008) Collective Interaction - Let's join forces. Presented at COOP'08 the 8th International Conference on the Design of Cooperative Systems. Provence, France May 20-23

[5] Petersen, M. G. (2007) Squeeze: designing for playful experiences among co-located people in homes. Shortpaper in $\mathrm{CHI}$ '07 Extended Abstracts on Human Factors in Computing Systems (San Jose, CA, USA, April 28 - May 03, 2007). ACM, New York, NY, 2609-2614.

[6] Thackara, J.,(2009):

http://www.doorsofperception.com/archives/BLOG.thackara.cumulus.TEXT-FINAL.pdf [7] Thackara, J (2001): The design Challenge of pervasive Computing, Interaction May - June 2001, ACM Press 